\title{
Antihypercholesterolemic Effect of Undigested Fraction of Soybean Protein in Young Female Volunteers
}

\author{
Ming-Fu WANG, Shigeru Yamamoto, ${ }^{1, *}$ Hei-Mei Chung, \\ Shu-Ying Chung, ${ }^{1}$ Shuichi Miyatani, ${ }^{2}$ Masahiro Mori, ${ }^{3}$ \\ Takuo OKITA, ${ }^{4}$ and Michihiro SUGANO ${ }^{5}$ \\ Department of Food and Nutrition, Providence University, Taichung, Taiwan \\ ${ }^{1}$ Research Center of Comprehensive Medicine, University of the \\ Ryukyus, Okinawa 903-01, Japan \\ ${ }^{2}$ Osaka Prefectural Junior College of Health Science, \\ Habikino 583, Japan \\ ${ }^{3}$ Department of Domestic Science, Kinran Junior College, \\ Suita 565, Japan \\ ${ }^{4}$ Fukuoka University of Education, Fukuoka 811-14, Japan \\ ${ }^{5}$ School of Agriculture, Kyushu University, Fukuoka 812, Japan
}

(Received June 18, 1994)

Summary The significant antihypercholesterolemic effect of the undigested high molecular fraction (HMF) of soybean protein is known in rats, but such an effect has not been shown in humans. The present two experiments were designed to elucidate it in humans. Subjects were female university students who had relatively high serum cholesterol levels for their age. In Experiment 1, subjects took 8\% of their total energy from casein, soybean protein isolate (SPI), or HMF daily for 14 days. Five basic menus and snacks were cycled. Energy intakes and daily activities were kept constant and body weight was maintained. The HMF group showed decreased low-density lipoprotein cholesterol (LDL-C) as compared to other groups. In Experiment 2, subjects took 4\% of total energy from casein or HMF daily for a menstruation period. Five basic menus and snacks which contained two egg yolks (about $500 \mathrm{mg}$ cholesterol) were cycled. Energy intakes and daily activities were kept constant and body weight was maintained. A decrease in LDL-C and an increase in high-density lipoprotein cholesterol (HDL-C) were observed in the HMF group as compared to the casein group. Fecal acidic steroid excretion was greater in the HMF group than in the casein group $(p<$ 0.05). The results confirmed that HMF increases fecal steroid excretion and reduces serum cholesterol levels in humans.

Key Words soybean protein, peptides, serum cholesterol, man

* To whom correspondence should be addressed. 
The antihypercholesterolemic effect of soybean protein has been confirmed by many researchers in animals (1-3), and in hypercholesterolemic (4-10) and normocholesterolemic (10-14) men. HMF, prepared after exhaustive digestion by microbial proteases, significantly decreased serum cholesterol levels compared to those observed with the parent protein in rats fed diets with (15) or without (16) cholesterol. HMF binds conjugated bile salts and significantly increases fecal excretion of both neutral and acidic steroids (17). However the effect of dietary protein on lipid metabolism is often different between rats and humans (10). In the study of rats, young animals are usually used and a large amount of single protein is given exclusively, while in the study of human, the subjects are usually adults and a portion of the mixed diets is usually replaced by the protein to be tested. Therefore, the results obtained in animal studies have to be confirmed in humans to evaluate the effects of HMF. The present two sets of experiments were designed to investigate this phenomenon in humans.

\section{MATERIALS AND METHODS}

Experiment 1. The subjects were female volunteer students of Providence University in Taiwan. The study protocol, which was in accord with the Helsinke Declaration was explained to each individual and informed consent was obtained. The experiments were also approved by the Ethical Committee of Providence University on Human Experiments. All the volunteers lived in the dormitory of the university.

The diets were prepared by a dietitian and served at the student cafeteria. Five types of basic meals and snacks were cycled during the experiment. Table 1 shows examples of such diets containing about $1,460 \mathrm{kcal}$. The intakes of nutrients were calculated using a food composition table $(18,19)$. Energy intake of the individual subjects was varied by increasing or decreasing the amount of steamed rice.

Examined nitrogen sources were soybean protein isolate (SPI, Fuji Oil Co., Osaka, Japan), HMF (Fuji Oil Co.), which was described previously (15) and casein (Morinaga Milk Industry, Tokyo, Japan). The subjects took $8 \%$ of total energy from one of these nitrogen sources. They took $2 \%$ with breakfast and $3 \%$ with each of lunch and dinner. The nitrogen concentration was determined by the Kjeldahl method. SPI, HMF, and casein contained 84,71 , and $84 \%$ protein, respectively. The nitrogen sources were supplied in a powdered form. Daily energy intake was decided by each subject and maintained constant throughout the experiment, about $31 \mathrm{kcal} / \mathrm{kg}$ body weight. Water, soy sauce, salt, spice, tea, and coffee were allowed freely.

A total of six subjects were divided into 3 groups. The first group took the nitrogen sources in the order of SPI, casein, and HMF; the second group HMF, SPI, and casein; and the third group casein, HMF, and SPI for the period of 14 days for each source. Body weight was measured every morning soon after waking up and urinating. Daily activities were measured by the pedometer (Calorie Counter 
$\alpha$, Suzuken, Nagoya, Japan) and maintained so that their body weight was kept constant. The subjects avoided strenuous physical exercises during the experiment. Fasting blood was withdrawn in the morning before and after the period of each diet and serum was kept frozen until analysis. Serum total cholesterol (Total-C), HDL-C, and triglycerides (TG) were measured by enzymatic kits (Wako Pure Chemical Industries, Osaka, Japan).

Experiment 2. In this experiment the effect of a smaller amount of HMF than that in Experiment 1 was studied in comparison with casein. A total of ten subjects were divided into two groups. They took either HMF or casein (4\% of total energy daily, $1 \%$ for breakfast, $1 \%$ for lunch and $2 \%$ for dinner) for one menstruation period (28-33 days). Feces of the last 3 days were collected, pooled by group and dried. Neutral (20) and acidic steroids (21) were analyzed by gas-liquid chromatography. Five basic meals and snacks shown in Table 1 plus two whole eggs daily containing about $500 \mathrm{mg}$ of cholesterol $(18,19)$ were cycled. Total energy was controlled by adjusting the amount of steamed rice. All the other conditions were similar to those of Experiment 1.

Statistical analysis. Data of Experiment 1 were analyzed by one-way analysis of variance followed by the inspection of all differences between pairs of means by Duncan's multiple-range test when variances were homogeneous. Data of Experiment 2 were analyzed by Student's $t$-test. Differences were considered significant at $p<0.05$.

\section{RESULTS}

Table 2 shows age, height, energy intake, daily activity, and changes in body weight and serum lipids, when the subjects were supplied $8 \%$ of energy from casein, SPI, or HMF for 14 days (Experiment 1). Body weight was maintained in all the subjects. Energy intakes and daily activities were similar among the three groups. LDL-C was calculated from serum Total-C, HDL-C, and TG by the method of Friedwald et al. (22) (LDL-C = Total-C-HDL-C-TG/5). Due to the relatively large individual variation of serum lipid level, the percentage change after the experiment in each subject is more appropriate to compare the results in this type of experiment. Decrease in Total-C was more marked in the HMF diet compared to other diets but the difference was not statistically significant $(p>0.05)$. HDL-C increased after feeding in the SPI and HMF groups more than in the casein group, but again without statistical significance $(p>0.05)$. The decrease in LDL-C was greater in the HMF group than in the other two groups $(p<0.05)$. Changes in LDL-C in the casein and SPI groups were similar.

Table 3 shows age, height, experimental period, energy intake, daily activity, changes in body weight, and serum lipids and fecal steroid excretion, when the subjects were supplied 4\% of energy from casein or HMF daily for a mensuration period, approximately 30 days on average. Age, height, energy intake, and daily activities were similar between the two groups. Body weight was maintained in all 
Table 2. Age, height, energy intake, daily activity, and changes in body weight and serum lipids ${ }^{1}$ (Experiment 1).

\begin{tabular}{lccc}
\hline & $\begin{array}{c}\text { Casein group } \\
(n=6)\end{array}$ & $\begin{array}{c}\text { SPI group } \\
(n=6)\end{array}$ & $\begin{array}{c}\text { HMF group } \\
(n=6)\end{array}$ \\
\hline Age (years) & $19.5 \pm 0.2$ & $19.5 \pm 0.2$ & $19.5 \pm 0.2$ \\
Height (cm) & $157 \pm 2$ & $157 \pm 2$ & $157 \pm 2$ \\
Energy intake (kcal/day) & $1,567 \pm 46$ & $1,567 \pm 46$ & $1,567 \pm 46$ \\
Daily activity (steps/day) & $9,787 \pm 564$ & $10,160 \pm 404$ & $9,654 \pm 453$ \\
Body weight & & & \\
$\quad$ Initial (kg) & $51.5 \pm 1.7$ & $51.7 \pm 2.0$ & $51.4 \pm 1.8$ \\
Final (kg) & $15.5 \pm 1.9$ & $51.3 \pm 1.8$ & $51.3 \pm 1.9$ \\
$\quad \%$ change) & $(99 \pm 0.9)$ & $(99 \pm 0.4)$ & $(100 \pm 0.4)$ \\
Serum lipids & & & \\
Triglycerides & & & $124 \pm 19$ \\
Initial (mg/dl) & $152 \pm 27$ & $114 \pm 2$ & $115 \pm 7$ \\
Final (mg/dl) & $132 \pm 27$ & $121 \pm 9$ & $(98 \pm 12)$ \\
$\quad$ (\% change) & $(88 \pm 11)$ & $(111 \pm 9)$ & \\
Total cholesterol & & & $212 \pm 5$ \\
Initial (mg/dl) & $219 \pm 4$ & $200 \pm 8$ & $194 \pm 6$ \\
Final (mg/dl) & $217 \pm 16$ & $214 \pm 8$ & $(92 \pm 3)$ \\
(\% change) & $(99 \pm 7)$ & $(107 \pm 4)$ & $39 \pm 3$ \\
HDL-cholesterol & & & $51 \pm 6$ \\
Initial (mg/dl) & $46 \pm 8$ & $42 \pm 5$ & $(129 \pm 9)$ \\
Final (mg/dl) & $44 \pm 2$ & $49 \pm 7$ & $149 \pm 5$ \\
(\% change) & $(98 \pm 11)$ & $(124 \pm 15)$ & $120 \pm 8$ \\
LDL-cholesterol ${ }^{4}$ & $141 \pm 5$ & $136 \pm 10$ & $\left(81 \pm 5^{\mathrm{b}}\right)$ \\
Initial (mg/dl) & $146 \pm 12$ & $141 \pm 8$ & \\
Final (mg/dl) & $\left(105 \pm 4^{\mathrm{a}}\right)$ & $\left(105 \pm 6^{\mathrm{a}}\right)$ & \\
(\% change) & & & \\
\hline
\end{tabular}

${ }^{1}$ Values are means \pm SEM. Values with different superscript letters indicate a statistically significant difference $(p<0.05)$. ${ }^{2}$ Measured by pedometer. ${ }^{3}$ Final value/initial value (\%). ${ }^{4}$ Total-cholesterol-HDL-cholesterol-triglycerides/5.

the subjects during feeding different proteins. Although changes in Total-C was not significantly different between the casein and HMF group $(p>0.05)$, HDL-C increased and LDL-C decreased significantly in HMF group than in the casein group $(p<0.05)$. Fecal acidic steroid excretion was significantly higher $(p<0.05)$ and neutral steroid excretion tended to be higher in the HMF group than in the casein group, although difference was not significant statistically $(p>0.05)$.

\section{DISCUSSION}

The results of the present two experiments suggest that HMF has a antihypercholesterolemic effect in female volunteers with mild hypercholesterolemia. In Experiment 1, the decrease of LDL-C was significantly greater in the HMF 
Table 3. Age, height, experimental period, energy intake, daily activity, and changes in body weight and serum lipids and fecal steroid excretion ${ }^{1}$ (Experiment 2).

\begin{tabular}{lcc}
\hline & $\begin{array}{c}\text { Casein group } \\
(n=5)\end{array}$ & $\begin{array}{c}\text { HMF group } \\
(n=5)\end{array}$ \\
\hline Age (years) & $22.0 \pm 0.4$ & $22.0 \pm 0.4$ \\
Height (cm) & $157.6 \pm 1.7$ & $159.9 \pm 3.2$ \\
Experimental period (day) & $30.8 \pm 1.5$ & $29.8 \pm 3.1$ \\
Energy intake (kcal/day) & $1,690 \pm 41$ & $1,740 \pm 45$ \\
Daily activity (steps/day) & $8,291 \pm 855$ & $8,678 \pm 1,081$ \\
Body weight & & \\
Initial (kg) & $52.0 \pm 1.7$ & $51.2 \pm 2.8$ \\
Final (kg) & $52.1 \pm 1.9$ & $51.4 \pm 2.8$ \\
(\% change) & $(100 \pm 1)$ & $(100 \pm 1)$ \\
Serum lipids & & \\
Triglycerides & & $110 \pm 23$ \\
Initial (mg/dl) & $87 \pm 12$ & $125 \pm 32$ \\
Final (mg/dl) & $74 \pm 7$ & $(118 \pm 25)$ \\
(\% change) & \\
Total cholesterol & $(88 \pm 8)$ & $225 \pm 17$ \\
Initial (mg/dl) & & $203 \pm 6$ \\
Final (mg/dl) & $218 \pm 12$ & $(92 \pm 13)$ \\
(\% change) & $218 \pm 12$ & \\
HDL-cholesterol & $(100 \pm 5)$ & $46 \pm 3$ \\
Initial (mg/dl) & & $49 \pm 5$ \\
Final (mg/dl) & $48 \pm 5$ & $\left(107 \pm 10^{*}\right)$ \\
(\% change) & $42 \pm 4$ & $158 \pm 19$ \\
LDL-cholesterol & $(88 \pm 6)$ & $129 \pm 10^{*}$ \\
Initial (mg/dl) & $153 \pm 10$ & $\left(84 \pm 7^{*}\right)$ \\
Final (mg/dl) & $161 \pm 8$ & \\
(\% change) & $(106 \pm 3)$ & $130 \pm 400$ \\
Fecal steroid excretion & & \\
Neutral steroids (mg/day) & $133 \pm 43$ & $115^{*}$ \\
Bile acids (mg/day) & & \\
\hline & & \\
\hline
\end{tabular}

${ }^{1}$ Values are means \pm SEM. ${ }^{2}$ Final value/initial value (\%). ${ }^{3}$ Total-cholesterol-HDLcholesterol-triglycerides/5. *Significant difference from the value of the control group by Student's $t$-test $(p<0.05)$.

group as compared to the SPI and the casein groups $(p<0.05)$. The changes of LDL-C were similar between the SPI and the casein groups. The effects of SPI and HMF diets on HDL $\mathrm{C}$ were similar and tended to be higher as compared with casein $(p>0.05)$. In Experiment 2, although the Total $\mathrm{C}$ remained unchanged in both groups, the increase in HDL C and the decrease in LDL.C were more marked in the HMF group than in the casein group $(p<0.05)$. These results were similar to those obtained in rats by Sugano et al. $(15-17)$. Rats fed an HMF diet showed a higher HDL-C level and a lower Total.C level than those fed an SPI diet (17). 
When the effects of SPI, HMF, and digestible low molecular fraction of SPI (LMF) on serum cholesterol were compared in rats, HMF had a much stronger antihypercholesterolemic effect than SPI, and LMF has a moderate hypercholesterolemic effect (15). Yamamoto and Inoue (10) reviewed the effects of soybean protein on plasma lipids in humans and concluded that soybean protein reduces LDL-C and increases HDL-C, which may also support our results.

Although the daily intake of HMF in Experiment 2 was half of that in Experiment 1, the antihypercholesterolemic effects of HMF in relation to casein was clearer in Experiment 2 than in Experiment 1. Namely, in Experiment 2 both LDL-C and HDL $-C$ were significantly different between the HMF and casein groups in contrast to the effect on LDL-C in Experiment 1. The major reason for these differences might be due to the difference in the feeding periods; it was about 30 days in Experiment 2, while it was 14 days in Experiment 1. Another important factor that may be involved is the difference in cholesterol intake. In Experiment 2 two eggs which contained about $500 \mathrm{mg}$ cholesterol $(18,19)$ was taken daily. Meinertz et al. (23) reported that when cholesterol intake was about $100 \mathrm{mg}$, serum cholesterol was not affected by the SPI diet, while when the intake was about 500 $\mathrm{mg}, \mathrm{LDL}-\mathrm{C}$ decreased and HDL-C increased.

As one of the mechanisms of the effects of HMF on cholesterol metabolism, Sugano et al. have suggested from the studies of rats that HMF produced in the lumen during digestion binds acidic steroids, causing them to be excreted into the feces $(15-17)$. In the present experiment in humans, acidic steroid excretion was significantly higher $(p<0.05)$ and the excretion of neutral steroids tended to be higher without statistical significance $(p>0.05)$ in the HMF group than in the casein group. A similar result has been reported in infants by the comparison of soybean milk and cow's milk (24). However, Sirtori and his group $(5,25)$ and Okuda et al. (26) did not observe the increased steroid excretion by the soybean protein diet. We suspect that the difference was due to the amount of HMF produced in the lumen from SPI. Since the soluble fraction of pepsin-digested SPI does not bind steroids (17), the excretion of steroids into the feces depends on the amount of the undigested fraction, HMF. The percentage of HMF in the pepsin-digested SPI is about $15 \%$. The daily intake of soybean protein was about $50(5,25)$ or $40 \mathrm{~g}(26)$, suggesting that up to 6 to $10 \mathrm{~g}$ of HMF is produced in the lumen. This was $1 / 3^{-1 / 2}$ of the HMF taken in Experiment 2. Sirtori and his group $(5,25)$ and Okuda et al. (26) observed a significant decrease in serum cholesterol by an SPI diet without an accompanying increase in fecal excretion of steroids. Saeki et al. (27) also showed that SPI was antihypercholesterolemic even when the absorption of cholesterol and bile acids was inhibited by resecting the jejunum and ileum in rats. Although these observations do not imply that increased steroid excretion contributes to the cholesterol-lowering effect, the present study showed that HMF stimulated fecal steroid excretion, suggesting that the mechanism of action of dietary protein is complex.

In summary, the present experiments showed that dietary HMF decreases 
LDL-C and increases HDL-C, which are partially attributable to increased fecal steroid excretion.

This research was supported by a Grant-in-Aid for Scientific Research in Priority Areas from the Ministry of Education, Science and Culture of Japan and by a grant from Fuji Oil Company, Osaka, Japan.

\section{REFERENCES}

1) Terpsta, A. H. M., Hermus, R. J. J., and West, C. E. (1983): The role of dietary protein in cholesterol metabolism. World Rev. Nutr. Diet, 42, 1-55.

2) Kritchevsky, D. K. (1990): Protein and atherosclerosis. J. Nutr. Sci. Vitaminol., 36, S81-S86.

3) Samman, S., Kurowaska, E. M., Khosla, P., and Carroll, K. K. (1990): Effects of dietary protein on composition and metabolism of plasma lipoprotein in rabbits. $J$. Nutr. Sci. Vitaminol., 36, S95-S99.

4) Sirtori, C. R., Agradi, E., Conti, F., and Gatti, E. (1977): Soybean-protein diet in the treatment of type-II hypercholesterolemia. Lancet, 1, 275-277.

5) Sirtori, C. R., Gatti, E., Mantero, O., Conti, F., Agradi, E., Tremoli, E., Sirtori, M., Fraterrigo, L., Tavazzi, L., and Kritchevsky, D. (1979): Clinical experience with the soybean protein diet in the treatment of hypercholesterolemia. Am. J. Clin. Nutr., 32, $1645-1658$.

6) Descovich, G. C., Gaddi, A., Mannino, G., Colombo, L., Cattin, L., Fontana, G., Senin, U., Mannarino, E., Caruzzo, C., Bertelli, E., Fragiacomo, C., Noseda, G., Sirtori, M., and Sirtori, C. R. (1980): Multicentre study of soybean protein diet for outpatient hypercholesterolaemic patients. Lancet, 2: 709-712.

7) Wolfe, B. M., Giovannetti, P. M., Cheng, D. C. H., Roberts, D. C. K., and Carroll, K. K. (1981): Hypolipidemic effect of substituting soybean protein isolate for meat and dairy protein in the diets of hypercholesterolemic men. Nutr. Rept. Int., 24, 11871198.

8) Goldberg, A. P., Lim, A., Kolar, J. B., Grundhauser, J. J., Steinke, F. H., and Schonfeld, G. (1982): Soybean protein independently lowers plasma cholesterol levels in primary hypercholesterolemia. Atherosclerosis, 43, 355-368.

9) Verrillo, A., Teresa, A., Giarrusso, P. C., and Rocca, S. L. (1985): Soybean protein diets in the management of type II hyperlipoproteinaemia. Atherosclerosis, 54, 321331.

10) Yamamoto, T., and Inoue, G. (1991): Effect of soybean protein on plasma cholesterol concentration in humans. Jpn. J. Food Nutr., 44, 155-162 (in Japanese).

11) Raaij, J. M. A., Martijin, B., West, C. E., and Hautvast, J. G. A. (1982): Influence of diets containing casein, soy isolate, and soy concentrate on serum cholesterol and lipoproteins in middle-aged volunteers. Am. J. Clin. Nutr., 35, 925-934.

12) Grundy, S. M., and Abrams, J. J. (1983): Comparison of actions of soy protein and casein on metabolism of plasma lipoproteins and cholesterol in humans. Am. J. Clin. Nutr., 38, 245-252.

13) Sacks, F. M., Breslow, J. L., Wood, P. G., and Kass, E. H. (1983): Lack of an effect of dairy protein (casein) and soy protein on plasma cholesterol of strict vegetarians. 
An experiment and a critical review. J. Lipid Res., 24, 1012-1020.

14) Mewinertz, H., Faergeman, O., Nilausen, K., Chapman, M. J., Godsterin S., and Laplaud, P. M. (1988): Effects of soy protein and casein in low cholesterol diets on plasma lipoproteins in normolipidemic subjects. Atherosclerosis, 72, 63-70.

15) Sugano, M., Yamada, Y., Yoshida, K., Hashimoto, Y., Matsuo, T., and Kimoto, M. (1988): The hypocholesterolemic action of the undigested fraction of soybean protein in rats. Atherosclerosis, 72, 115-122.

16) Ogawa, T., Gatchalian-Yee, M., Sugano, M., Kimoto, M., Matsuo, T., and Hashimoto, Y. (1992): Hypocholesterolemic effect of undigested fraction of soybean protein in rats fed no cholesterol. Biosci. Biotech. Biochem., 56, 1845-1848.

17) Sugano, M., Goto, S., Yamada, Y., Yoshida, K., Hashimoto, Y., Matsuo, T., and Kimoto, M., (1990): Cholesterol-lowering activity of various undigested fractions of soybean protein in rats. J. Nutr., 120, 977-985.

18) Tung, T. C., Huang, P. C., and Li, H. C. (1981): Composition of foods used in Taiwan. J. Formosan Med. Assoc., 60, 973-1005.

19) The Science and Technology Agency (ed.) (1982): The Japanese Food Composition Table, 4th Ed. Jyoshi Eiyo Daigaku Shuppanbu, Tokyo, pp. 46-355 (in Japanese).

20) Miettinen, T., Ahrens, E. H., and Grundy, S. M. (1965): Quantitative isolation and gas-liquid chromatographic analysis of total dietary and fecal neutral steroids. J. Lipid Res., 6, 411-424.

21) Grundy, S. M., Ahrens, E. H., and Miettin, T. (1965): Quantitative isolation and gas-liquid chromatographic analysis of total fecal bile acids. J. Lipid Res., 6, 397-410.

22) Friedwald, W. T., Levy, R. T., and Fredrickson, D. S. (1972): Estimation of the concentration of low density lipoprotein cholesterol in plasma without the use of the preparative ultracentrifuge. Clin. Chem., 18, 499-502.

23) Meinetz, H., Nilausen, K., and Faergeman, O. (1989): Soy protein and casein in cholesterol-enriched diets: Effects on plasma lipoproteins in normolipidemic subjects. Am. J. Clin. Nutr., 50, 786-793.

24) Potter, J. M., and Nestle, P. J. (1976): Greater bile acid excretion with soybean than with cow milk in infants. Am. J. Clin. Nutr., 29, 546-551.

25) Sirtori, C. R. (1982): Fecal cholesterol excretion studies in type II hypercholesterolemic patients treated with the soybean protein diet. Atherosclerosis, 43, 341-353.

26) Okuda, T., Miyoshi, H., Sasaki, K., Satake, R., Hiratuka, Y., and Koishi, H. (1988): Effects of soy protein isolate on fecal sterol excretion and plasma cholesterol in young men. Nutr. Sci. Soy Protein, 9, 97-100 (in Japanese).

27) Saeki, S., Nishikawa, H., and Kiriyama, S. (1987): Effects of casein or soybean protein on plasma cholesterol level in jejunectomized or ileectomized rats. J. Nutr., 117, 15271531 . 